\title{
Analysis of the existing problems for attracting inward foreign direct investment in Shanghai Ying Zhu
}

\author{
School of Business East China University of Political Science and Law, 201620
}

E-mail: zhuying200901@163.com

Keywords: Shanghai, foreign direct investment, foreign capital, adjustment

\begin{abstract}
Shanghai's economy enter a new stage at present, so foreign direct investment will adjust accordingly. The paper analyzes the non-reasonability of foreign direct investment in Shanghai in this time: Firstly, the declining proportion of manufacture FDI hampers the achievement of Shanghai's goal of becoming a global innovation center. Secondly, investment industry segmentation and investment orientation shall be guided more reasonably. Thirdly, foreign capital origins to Shanghai are excessively concentrated. Investment source shall be optimized. Fourthly, the content of inward capital is badly in need of change. Fifthly, there is a mismatch between demand and supply of inward foreign capital. Sixthly, great efforts should still be made to achieve the goal of improving the technical ability with foreign capital. Seventhly, foreign- enterprises are being squeezed out due to high survival cost. In short, Shanghai needs to change the form and content of foreign investment.
\end{abstract}

\section{Introduction}

On February 12, 2014, briefing of Shanghai business situation showed that, Shanghai has achieved another historically high watermark of inward foreign direct investment (FDI) in the scale. The efficiency of FDI utilization was also enhanced. Both growth rates of contractual and realized foreign capital inflow were over $10 \%$ all year round on annual basis. Shanghai has been open for foreign capital for over 30 years, and the overall situation is persistently improving. However, in the recent years, due to the changes in the global economic environment, needs of industrial development and industrial structure upgrading, there are new needs on foreign capital. Nevertheless, due to the structural problems in the inward FDI, there are certainly more things to be desired in using these inward FDI to promote the industrial structure reformation and upgrading in Shanghai.

1. The declining proportion of manufacture FDI hampers the achievement of Shanghai's goal of becoming a global innovation center

After the financial crisis of 2008, scale of foreign capital introduced by tertiary industry is on the rise, introduction of foreign capital by secondary industry presents the fluctuation and downward trend on the whole. The proportion of foreign capital amount utilized by Shanghai industrial projects to total foreign capital amount falls from 19.75\% in 2010 to $9.59 \%$ in 2013 (see Fig. 1). This trend reflects the goals of Shanghai industrial policy guidance. However, Shanghai is currently aiming to establish a global innovation center, and the inward manufacture industry FDI can foster technological innovation. Therefore, the strategic economic development goals of Shanghai can only be achieved by improving the diversity of inward FDI.

Figure 1 Proportion of contractual foreign capital used by industrial projects in Shanghai (2010-2013) 


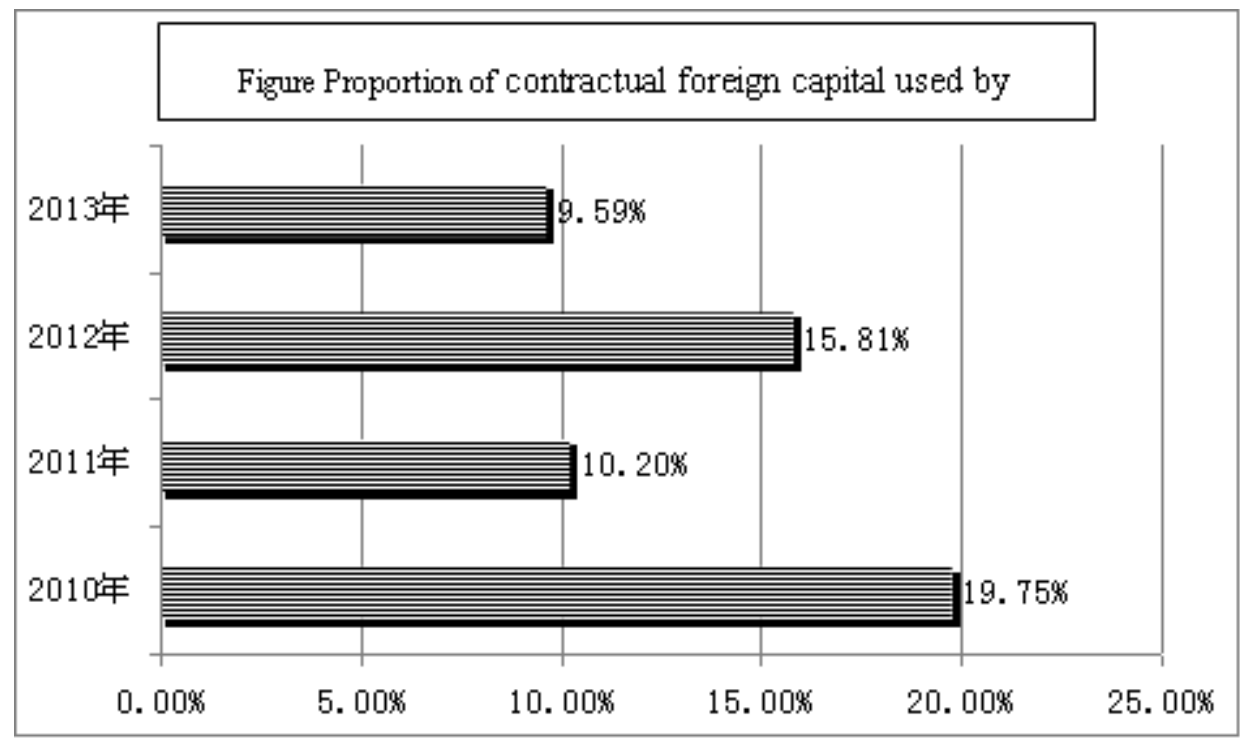

Note: sorted out as per Shanghai industrial statistical data in 2010, 2011, 2012 and 2013

\section{Investment industry segmentation and investment orientation shall be guided more} reasonably

The data of the first half year of 2014 (see Fig. 2) shows that, foreign merchants are more likely to make direct investment in the industries with high profit and short production cycle, such as service industry, real estate industry, wholesale and retail industry, and financial industry. Even in the manufacturing industry, most of inward FDI is in the simple manufacturing processes. However, the badly needed high tech industrial projects are insufficient. In particular, the ratio of high tech inward FDI to overall FDI should be increased. Without proper guidance from the government industrial policies, the inward FDI flow will deviate from the desired long term economic development objectives in Shanghai.

Figure 2 Proportion of contractual foreign capital amount for industries from January to June 2014

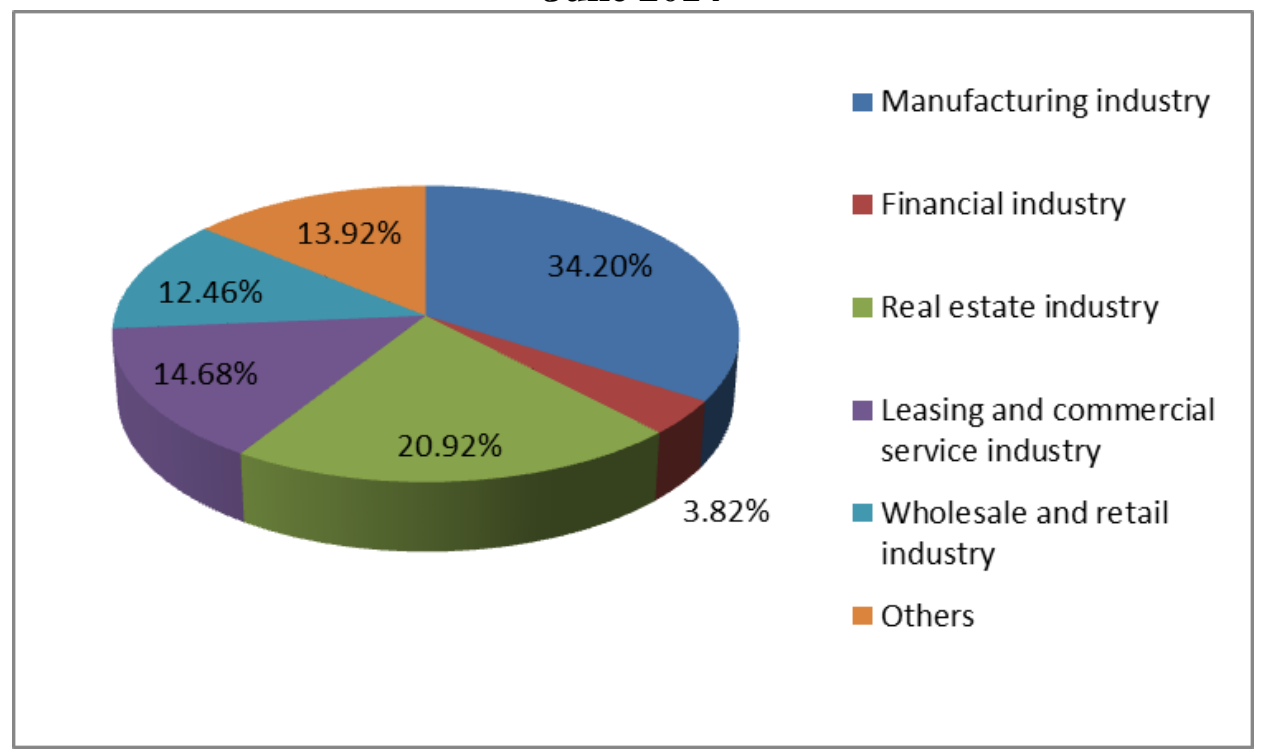

Note: sorted out as per the monthly statement of Shanghai foreign capital utilization statistics (June 2014)

\section{Investment source shall be optimized}

Fig. 3 and Fig. 4 indicate that foreign capital origins to Shanghai are excessively concentrated. Proportion of investment from Hong Kong and Taiwan, as well as neighboring countries Japan and Korea are greater, while investment from European and American countries are small. Distribution of foreign investment origin is not reasonable: most foreign capital is introduced from Hong Kong, Taiwan and Asian region, while investment from transnational corporations of European and 
American developed countries are slightly insufficient. Nevertheless, historical data shows that investment by transnational corporations of European and American countries can better attract future inward FDI. Moreover, with powerful R\&D strength, European and American companies are vitally important for the technological upgrades of Shanghai enterprises. Due to lack of stimulation and competition from the exogenous force, introduction of foreign capital for Shanghai forms "path dependence". So, foreign capital is mainly from Asian region. For this reason, Shanghai must adjust capital attraction policy, break the current "path dependence", and form a new capital attraction pattern, so as to promote leapfrog development of industries and enterprises in Shanghai.

\section{Figure 3 Number of foreign investment project of different countries or regions from January} to June 2014

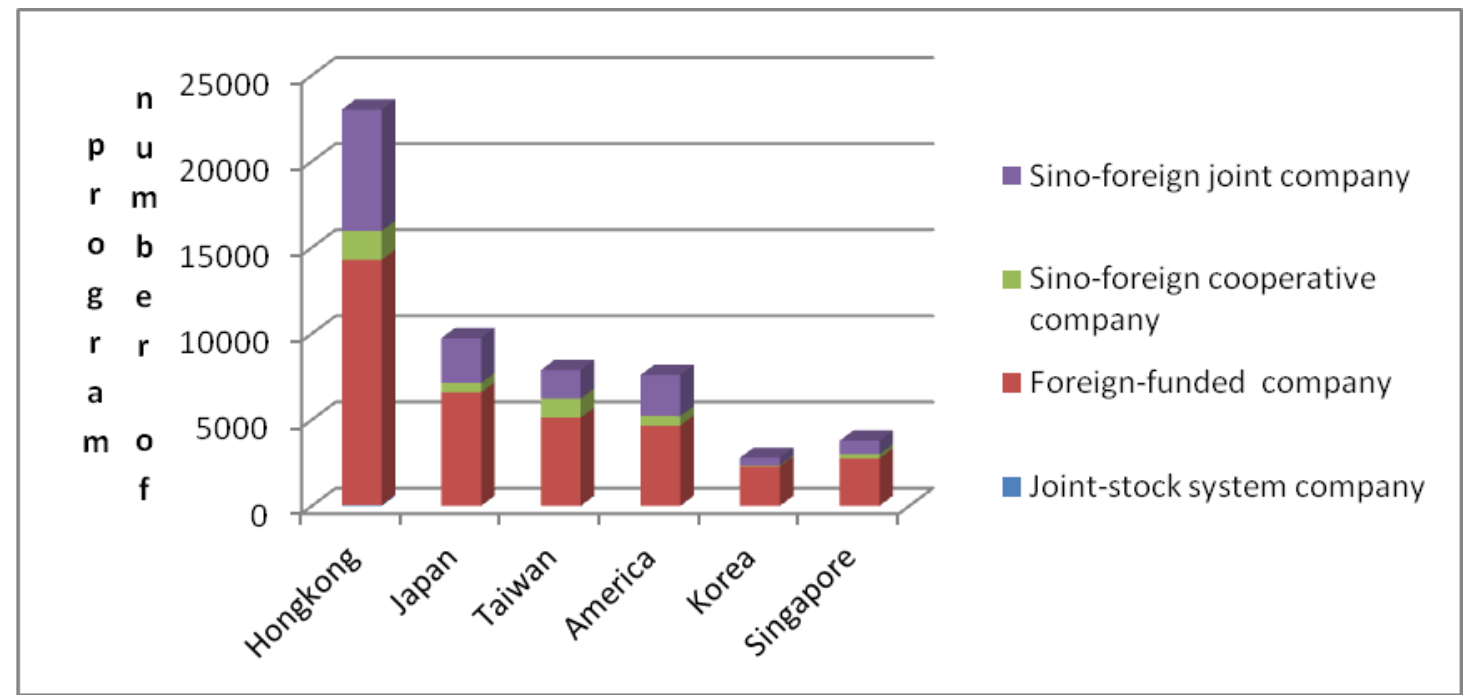

Note: sorted out as per the monthly statement of Shanghai foreign capital utilization statistics (June 2014)

Figure 4 Number proportion of foreign investment projects of different countries or regions from January to June 2014

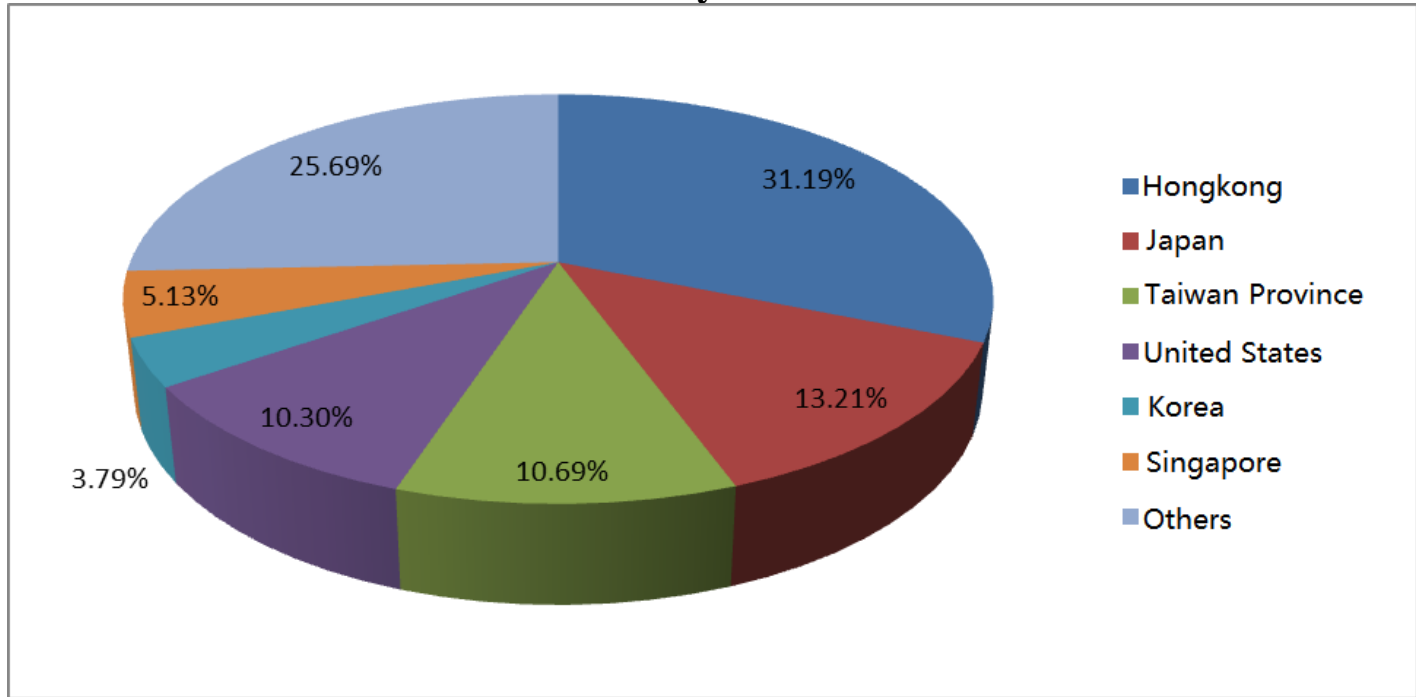

Note: sorted out as per the monthly statement of Shanghai foreign capital utilization statistics (June 2014)

\section{The content of inward capital is badly in need of change}

At the initial stage of economic development for Shanghai, due to the urgent needs, Shanghai tended to lay emphasis on the inward production and cash flow volume, rather than the technology and human capital content of the foreign capital inflow. Although such capital attraction mode at the initial stage has met the capital requirement in the initial development stage, the excessive attention to cash flow introduction fails to meet the current situation at a more advanced economic development stage, and will surely impede the development of industries in Shanghai. Therefore, it 
is important to greatly improve the content of foreign capital attraction.

\section{A mismatch between demand and supply of inward foreign capital}

At the early stage of economic development for Shanghai, introduction of foreign capital was indiscriminate, obviously driving the economic development at that time. Nevertheless, such way of introduction has brought adverse consequences, namely, high technology foreign capital with beneficial spillover effect is insufficient, and the inflow of capital concentrates on low end manufacturing and service industries. Besides, the attractiveness is not sufficient for the strategically important emerging industries and high R\&D industries desired by Shanghai government.

\section{Great efforts should still be made to achieve the goal of improving the technical ability with foreign capital}

A main purpose for Shanghai government to introduce foreign capital is to induce technology advances, and upgrade technology level of local enterprises. Nevertheless, there is gap between the reality and the goal: (1) with the constantly mature consumer market in Shanghai, some local enterprises have achieved significant development at technology integration and innovation ability, while due to selfishness, and the motivation of profits, quite a few foreign companies realize internalization of technology usually by means of sole proprietorship and/or increase in ownership percentage , etc., so as to strengthen their monopoly control of technology and reduce technological spillovers. Because they worry about the possible loss of control on technology, therefore loss of bargaining power for the future negotiation, against their Chinese local partner enterprises.; (2)due to either inertial or lack of self-confidence, domestic enterprises always believe that their technical level is low, so they adore and depend too much on their foreign partners. The above inertial coupled with the lack of protection on innovation in the institutional environment, local enterprises lack the motive for proactively absorbing and surpassing technologies of foreign-funded enterprises. Therefore, as to foreign capital introduction, Shanghai shall focus on how to promote technology upgrading of local enterprises via effective utilization of foreign capital.

\section{Foreign- enterprises are being squeezed out due to high survival cost}

In recent years, with the rapid development of Shanghai, price of land and rent expenses are constantly increasing, and business costs are also rising constantly thereupon, for instance: office building rent, utility expenses and labor cost increase at varying degrees. Fast-rising of these costs enables operating costs of foreign enterprises to rise greatly, affecting their investment choice in Shanghai. So many foreign companies choose to switch to cities with relatively low costs. Along with other reasons, foreign enterprises have to adjust investment strategy in Shanghai. However, just as a coin has two sides, many squeezed-outs foreign enterprises are low-technology, labor intensive, high pollution and high energy consumption. They entered Shanghai decades ago for the cheap labor cost and a variety of preferential policies, without significance contribution to the modern development needs of Shanghai. So, withdrawal of these enterprises is favorable for the optimization and upgrading of industrial structure of Shanghai

Based on the above analysis, for the new goals at the new economic development stage, Shanghai shall adjust the content, level, and industry structure of the inward foreign capital. Foreign capital badly needed by the current development of Shanghai can only be attracted with innovative policies, thus facilitating industrial structure transformation and upgrading, as well as achieving the strategic goal of building a global innovative center.

\section{ACKNOWLEDGEMENTS:}

This article are supported by the following projects: (1) Social and Scientific research Project of Chinese Ministry of Education (No.: 14YJA630100); (2) Research Project of East China University of Politics Science and Law (No.: 10H2K010); (3) 085 International Platform Project of East China University of Politics Science and Law (No.: A-3101-14-4112)

\section{References:}


[1]. Xiao Yao. Improvement of Capital Introduction Structure for Shanghai and Discussion of New Capital Introduction Policy of Service Industry [N]. First Financial Daily A04, July 16, 2010

[2]. Jin Fang. Path and Countermeasures of Promoting Shanghai Industrial Development Level under Intra-Product Specialization Conditions [J]. Shanghai Economic Review, 2007, 07: 58-64.

[3]. Wang Haiyan. Problems, Countermeasures and Proposals of the Introduction of Foreign Capital [J]. Digest of Management Science, 2013, 26:110-111.

[4]. Yang Dakai. Research on the Introduction of Foreign Capital in Shanghai under New Situation [J]. Scientific Development. 2012, 08:24-42.

[5]. Fernandes Ana M. Services FDI and Manufaturing Productivity Growth: There is a Link[R]. The World Bank, 2008:1-54. 